\title{
The Twentieth Annual Exhibition of the Physical Society and the Optical Society.
}

THE exhibitions of electrical, optical, and other scientific apparatus arranged by the Physical and Optical Societies have grown steadily in interest and importance year by year, and that held on Jan. 7, 8 , and 9 last was decidedly the most successful of all. The exhibition was housed, as usual, in the Imperial College of Science, and although additional accommodation was allotted, the available space was filled to compression with extremely interesting exhibits.

An important new section has been introduced, with the object of encouraging craftsmanship in the scientific instrument trade. Prizes were offered to apprentices and learners for the best examples of craftsmanship and for the best designs, drawings, or tracings. All too little has been done in the past to encourage young instrument-makers to take a pride in their art, and it was gratifying to see the high standard attained. As the competition was the first of its kind, readers of NATURE may be interested to know the results in detail. They were as follows: Class $A$, Craftsmanship : senior grade (18-21 years) : (1) J. H. Richards (Creed and Co., Ltd.), perforator punch block; (2) P. D. Betteridge (Griffin and Tatlock, Ltd.), voltmeter movement, and A. Mead (Adam Hilger, Ltd.), micrometer eyepiece; honourable mention: S. W. Angel (Negretti and Zambra), Bourdon tube and spindle, and W. G. Sibley (H. Tinsley and Co.), six-dial resistance box. Junior grade (under 18 years) : (1) E. G. Sawyer (Negretti and Zambra), geared movement of quadrant form ; (2) R. H. Brockman (Adam Hilger, Ltd.), proof plane of quartz. Class $B$, Draughtsmanship : senior grade : (1) H. Downing (General Electric Co., Ltd.); (2) E. G. Baker (George Kent, Ltd.) and E. Lowings (George Kent, Ltd.); honourable mention, A. G. Haslam (H. W. Sullivan, Ltd.). Junior grade : (1) S. W. Holdstock (George Kent, Ltd.), (2) E. F. Woods (George Kent, Ltd.). Scientific progress depends directly on the skill of the instrument-maker, and the stimulus provided by a competition of this kind should therefore prove decidedly beneficial.

The number of exhibits in the remaining sections was so great that it is out of the question to do justice to them in a short article. A full account of the most interesting will be found in the catalogue, which has been printed in a form suitable for binding up with the proceedings of the participating societies. Here it is possible only to mention briefly a few items which happened to attract the attention of the writer, and a different observer might well have made a different selection.

The section devoted to research and experiment, another feature which has recently been added to the exhibition, is expanding in a satisfactory manner. Group $A$ comprised nearly a hundred exhibits illustrating recent research. Those contributed by the National Physical Laboratory included a wireless oscillator for wave-lengths down to 1.5 metres and a direction-finder for wave-lengths of 4-10 metres; a 0.00002-ohm standard resistance for direct current up to 20,000 amperes, consisting of 40 parallel watercooled manganin tubes joining two copper dises, to the peripheries of which a number of cables are symmetrically connected in parallel, the arrangement being designed to avoid errors arising from variation of eurrent distribution in the end-connexions; and a demonstration of the use of the hot-wire anemometer for detecting turbulent flow. In the latter a hot wire, in circuit with an amplifier feeding a loud-speaker, is situated close to the surface of a stream-lined body in a blast of air. Normally the loud-speaker is silent, but disturbance of the flow by the interposition of a pencil or the like produces loud sounds. Messrs. R. W. Paul and B. S. Cohen showed a series of loudspeaker diaphragms made of balsa wood, an extremely light and stiff material : the response curves actually measured are found to correspond closely with curves predicted on the assumption that the diaphragms are rigid.

In a Kundt's tube excited by a valve-driven diaphragm, demonstrated by Prof. E. N. da C. Andrade and Mr. S. K. Lewer, the dust particles are found to form sharp and accurately measurable rings at the antinodes, the amplitude of vibration of individual particles can be observed directly (the particles being seen as short lines parallel to the axis of the tube), and the tube is sealed to preserve the purity of the gas (see Nature, Nov. 9, 1929, p. 724). A solution has been provided by the British ThomsonHouston Co., Ltd., of a problem which must have racked the brains of many youthful electricians, namely, the transformation at high efficiency of direct-current supply. For this purpose a mercury vapour rectifier having an oxide-coated hot filament as cathode and a magnetic control is used. This rectifier has several interesting properties and will probably be put to many uses. For the purpose of direct-current transformation, it is made to commutate the low-tension supply, and the resulting alternating voltage, after being stepped up by an ordinary transformer, is rectified to yield a hightension direct-current output.

A curious experiment on weak suspensions of clay was contributed by the Rothamsted Experimental Station. When the solid matter forms a few per cent of the whole, the suspension behaves as a liquid for ordinary stresses, but as an elastic solid for very small shearing stresses, the critical value of the stress increasing rapidly with concentration. A viscometer of the rotating-cylinder type was demonstrated, the outer cylinder, which contains the clay, being suspended, while the inner revolves. For very slow speeds of rotation the torque increases regularly with speed, but when the shearing stress exceeds the critical value a very large increase in the speed makes little difference to the torque. The Research Laboratories of the Gramophone Co., Ltd. (H.M.V.), and the Marconiphone Co., Ltd., also demonstrated a mag. netically controlled mercury vapour relay, and another interesting feature of their stand was a cathode ray oscillograph arranged to show, on a time base, the dying away of a sound picked up by a microphone in the hall, the sound-supply being eut off suddenly after a steady distribution of soundintensity had been attained. Messrs. C. E. WynnWilliams and Ward showed apparatus for counting the passage of $a$-particles based on the usual principles, but having the unusual feature that the impulses initiated by the passage of the particles are applied to a mechanical counter, the number-cylinders of which are seen to move step by step as the particles emerge.

A good deal of ingenuity can be exercised in the devising of lecture-experiments and teaching-apparatus of an inexpensive type, and this year the section of the exhibition devoted to such matters was very well supported. A very fine collection of improvised apparatus was shown by Mr. F. A. Meier, of Rugby, the most striking being, perhaps, that in which a diffraction pattern is formed by means of three steel balls in contact. Talbot's bands were produced by Mr. A. C. G. Beach (Chelsea Polytechnic) by placing between a spectrometer and an observing telescope an additional slit having half its width occupied by 
a strip of celluloid film. Paper-clips of the 'bulldog' type have often featured in apparatus constructed by hard-pressed teachers under the stress of enforced economy, but the usefulness of these factotal objects has been much extended by Mr. D. G. A. Dyson by the addition of brass terminals, which facilitate attachment to the steel rods that figure in improvisations of the kind in question. Mr. J. E. Calthrop, of East London College, has devised a simple hydrometer for measuring surface tension; it consists of a glass vessel made of two cylinders of different diameters having their axes in line. The vessel is loaded with mercury so that it floats vertically with either end uppermost, and the volumes which stand above the surface of the liquid in the two positions differ by an amount which gives the surface-tension in absolute units.

In the trade section the largest share of attention was attracted by those firms-happily a large and increasing number-which enter into the spirit of the exhibition and contrive to make their stalls scientifically interesting. There is still a certain number of firms who are content to set up a kind of shop window full of unedifying boxes with terminals or eyepieces on their outsides, but the more enterprising exhibitors contrived to provide excellent demonstrations or dis-assembled instruments, and even they were far too numerous for individual mention. The Cambridge Instrument Co., Ltd., had, as usual, a very fine display of new apparatus. Among the instruments which attracted our attention was a seismograph for detecting salt domes and for locating geological faults; it was noteworthy for a delicate and effective application of the toggle principle for multiplying movement. The same firm showed a recording colorimeter in which light, after passing through solution the colour-density of which varies with time, affects a photo-electric cell which controls a thread recorder. The current supply is drawn from the mains and ripple is eliminated by an ingenious device ; the filament of a triode valve is heated with alternating current, and the anode is supplied through a resistance with rectified current from the same source; fluctuations in the mains vary both the valve impedance and the potential drop in the resistance in such a way that the effects of these variations cancel one another. The Ashdown rotoscope, manufactured by Elliott Bros. (London), Lt.d., for observing objects in periodic motion and measuring their periodicity, is a stroboscope with a useful feature for rendering the view of the object instantaneous, while permitting good apparent illumination: the shutters consist of rotating sets of parallel laminæ, so that a good instantaneous view is afforded when the laminæ are horizontal, but a very sharp cut-off is effected as soon as the laminx have rotated through a small angle. Among Messrs. Hilger's exhibits was a system for spectrographic analysis by Barratt's method. Two spark gaps, one having electrodes of known composition, while the other has electrodes of the substance under test, are connected in series so as to take the same current, and the relative intensities of the same spectral line when derived from each of the two gaps are found by means of a photometer of the polarisation type.

The M.O. Valve Co., Ltd., set an excellent example by installing an automatic grid-making machine, which was seen in action. Nothing is more interesting to visitors than a glimpse of manufacturing processes such as the one thus afforded. It is, however, im. possible to do more than pick out, more or less at random, a few plums from the embarrassingly rich fare provided.

Discourses were delivered as follows: on Jan. 7, Lord Rayleigh on "Iridescent Colours in Nature from the Standpoint of Physical Optics" ; on Jan. 8 , Mr. S. G. Brown on "Gyro-Compasses for Gun-Fire Control"; and on Jan. 9, when the general public was admitted free, Sir Ambrose Fleming on "Television, Present and Future".

\section{Prize Awards of the Paris Academy of Sciences.}

$\mathrm{A}^{\mathrm{T}}$ the annual public meeting of the Paris Academy of Sciences, held on Dec. 16, the prize awards for the year were announced as follows :

Mathematics.-The Francœur prize to Paul Noaillon, for his researches in mathematical analysis and hydrodynamies.

Mechanics.-The Poncelet prize to Alfred Liénard, for his works on the application of the general theories of mechanics to the problems of electrostatics, electrodynamics, and magnetism; the Henry Bazin prize to Charles Camichel, for his experimental study of eddies in liquids with the aid of metallic particles in suspension.

Astronomy.--The Lalande prize to Alexandre Véronnet, for the whole of his astronomical work concerning the figure and constitution of the heavenly bodies; the Damoiseau prize to Gaston Fayet, for his memoir on the eccentricities of cometary orbits; the Valz prize to Louis Dunoyer, for his researches on spiritlevels and photoelectric cells.

Geography.-The Gay prize to Ludovic Gaurier, for his work on the lakes of the Pyrenees; the Tchihatchef foundation to Paul Pollacchi, for his French colonial atlas.

Navigation.-Prize of the Ministry of Marine to (the late) Eugène Emery, for the whole of his work; the Plunoy prize to Pierre Clerget, for his improve. ments in motors for air navigation.

Physics.-The Gaston Planté prize to Charles Féry, for his work on the theory of the lead accumulator; the Hébert prize to Georges Déjardin, for his researches on ionisation potentials and on the classification of spectral lines of various atoms; the Henri de Parville prize to Marcel Pauthenier, for his work on Kerr's electro-optical phenomenon; the Hughes prize to Jean Jacques Trillat, for his researches on molecular orientation made by means of the X-rays; the Clément Félix foundation to René de Mallemann, for his work on rotatory polarisation.

Chemistry.-The Montyon prize (unhealthy trades) to Daniel Florentin, for his work on the hygiene of large towns; the Jecker prize between Richard Fosse, for his work in agricultural, biological, and organic chemistry, and Marcel Sommelet, for the whole of his work in organic chemistry; the Cahours foundation between Henri Moureu, for his researches on the tautomerism of the a-diketones, and Raymond Quélet, for his work on certain derivatives of benzene; the Houzeau prize to André Travers, for his work in inorganic and analytical chemistry.

Mineralogy and Geology.-The Delesse prize to Marius Dalloni, for his geological work on northern Spain and Algeria; the Fontannes prize to Alfred Carpentier, for his work on palæobotany ; the Victor Raulin prize to Pierre Bonnet, for his geological work on Armenia.

Botany.-The Desmazières prize to Hubert Bourdot, for his work on the Hymenomycetes of France; the Montagne prize between Pierre Dangeard (1000 francs), for his memoir on Bangia and Porphyra, and Robert Potier de la Varde ( 500 franes), for his work in bryology; the Thore prize to Charles Douin, for his work on the 